\title{
Pemanfaatan Media Sosial Sebagai Komunikasi Kreatif Institusi Pendidikan Tinggi Indonesia di Masa Pandemi COVID-19
}

\author{
Haris Suhendra \\ Marketing Communication Program, Communication Department \\ Faculty of Economics \& Communication, Bina Nusantara University \\ Jakarta 11480, Indonesia \\ haris@binus.edu
}

Correspondence: haris@binus.edu

\begin{abstract}
The COVID-19 pandemic has forced higher education institutions to change the way they communicate so that the number of new students can continue to grow. The use of social media is a strategy for higher education institutions that must be carried out in building awareness and strong relationships with students and alumni to achieve this growth. Therefore, this study aims to look at the performance of social media during the COVID-19 pandemic by examining upload movement activities on social media. The focus of this research is using social media analytics through performance metrics Impressions, Audience Demographics \& Growth, Publishing Behavior, Engagement. The object of this research is to study all activity uploads on Facebook, Instagram and Tiktok during the period July 1, 2020 to June 30, 2021. The frequency of uploads is collected per day and analyzed for one year. This study analyzes the content, frequency and time period of uploads on Facebook, Instagram and Tiktok. The results of this study show the performance of Social Media metrics on Instagram, Facebook and Tiktok by comparing the performance of the research period taken in this study with the previous one year period. Higher Education Institutions are advised to use Social Media as an effective creative communication channel to build the advantages of Higher Education Institutions and build relationships with the public during the COVID-19 pandemic.
\end{abstract}

Keywords: Facebook; Instagram; Creative Communication; Social Media; Higher Education

\begin{abstract}
ABSTRAK
Pandemi COVID-19 telah memaksa berubah cara berkormunikasi Institusi Pendidikan Tinggi agar dapat tetap bertumbuh akan jumlah mahasiswa barunya. Penggunaan Media Sosial menjadi strategi Institusi Pendidikan Tinggi yang harus dilakukan dalam membangun kesadaran dan hubungan yang kuat dengan mahasiwa dan alumni untuk mencapai pertumbuhan tersebut. Oleh karenanya, penelitian ini bertujuan untuk melihat kinerja Media Sosial di masa pandemi COVID-19 dengan meneliti aktifitas pergerakan unggahan di Media Sosial. Fokus penelitian ini menggunakan social media analytics melalui kinerja metrik Impressions, Audience Demographics \& Growth, Publishing Behavior, Engagement. Objek penelitian ini mempelajari semua unggahan aktifitas di Facebook, Instagram dan Tiktok selama periode 1 Juli 2020 hingga 30 Juni 2021. Frekuensi unggahan dikumpul perhari dan dianalisa selama satu tahun. Penelitian ini menganalisa isi, frekuensi dan periode waktu unggahan di Facebook, Instagram dan Tiktok. Hasil penelitian ini diperlihatkan kinerja metrik Media Social di Instagram, Facebook dan Tiktok dengan membandingkan kinerja periode penelitian yang diambil dalam penelitian ini dengan periode satu tahun sebelumnya. Institusi Pendidikan Tinggi disarankan untuk menggunakan Media Sosial sebagai saluran komunikasi kreatif yang efektif untuk membangun keunggulan Insitusi Pendidikan Tinggi dan membangun hubungan dengan khalayak publik dimasa pandemi COVID-19.
\end{abstract}

Kata Kunci: Facebook; Instagram; Komunikasi Kreatif; Media Sosial; Pendidikan Tinggi 


\section{PENDAHULUAN}

Pandemi COVID-19 sudah 18 bulan mendera Indonesia sejak pemerintah menetapkan penderita Covid-19 pertama di Indonesia pada Maret 2020. Per Juli 2021, terkonfirmasi positif 2.911.733 orang. sembuh 2.293.711 orang dan meninggal 74.920 orang (COVID-19, 2021). Tak hanya menciptakan krisis kesehatan masyarakat, pandemi Covid-19 secara nyata juga menggangu aktifitas perekonomian di berbagai sektor industri kecil, menengah maupun besar (Perindustrian, Kementerian, 2020).

Pandemi COVID-19 juga membawa pengaruh yang sangat besar bagi dunia pendidikan. Hingga saat ini, pemerintah masih mempertimbangkan dengan cermat mengeluarkan keputusan untuk belajar seperti sedia kala walau sempat ingin dibuka, namun diurungkan kembali dikarenakan terjadi kanaikan yang terkonfirmasi positif COVID-19. Melihat dari kondisi tersebut tentunya semenjak Menteri pendidikan mengeluarkan Surat Edaran Nomor 3 Tahun 2020 Tentang Pencegahan Corona Virus Disease (COVID-19) Pada Satuan Pendidikan yang menyatakan bahwa meliburkan Sekolah dan Institusi Pendidikan Tinggi (Kemendikbud, 2020). Hal ini dilakukan untuk memutus mata rantai penyebaran COVID 19, sebagai gantinya kegiatan pembelajaran dilakukan secara daring untuk semua jenjang pendidikan. Institusi Pendidikan Tinggi berpikir keras bagaimana menjalankan kegiatan belajar-mengajar agar tetap berjalan, antara lain dengan memanfaatkan teknologi dengan cara daring.

Tidak hanya berdampak pada pengajaran saja, dalam memperoleh calon mahasiswa baru pun terdampak, sehingga dituntut harus berpikir kreatif untuk dan memberikan solusi masa depan melalui penyajian informasi tentang keunggulan pendidikan tinggi dan membangun hubungan berkelanjutan antara mahasiswa, orang tua, alumni dan khalayak publik.

Oleh karenanya diperlukan peran teknologi informasi yang mumpuni untuk membangun layanan informasi secara daring hingga segala transaksi kebutuhan perkuliahan secara daring. Salah satunya adalah bagaimana pemanfaatan platform Media Sosial sebagai komunikasi kreatif Institusi Pendidikan Tinggi Indonesia di masa pandemi COVID-19.

Perkembangan teknologi informasi di Indonesia, jumlah pengguna internet di Indonesia naik 73,7\% dari populasi Indonesia yang 274,9 juta atau menembus 202,6 juta pengguna. Selama setahun terakhir, terjadi penambahan 27 juta pengguna.

Hal menarik, waktu yang digunakan untuk mengakses internet juga meningkat, dari 7 jam 59 menit menjadi 8 jam 52 menit. Dengan penggunaan untuk chat (96,5 persen), jejaring sosial (96,3 persen), shopping (78,2 persen), layanan keuangan (39,2 persen), entertainment (86,2 persen) dan lainnya. (WeAreSocial, 2021)

Pengaruh jaringan Media Sosial pada kehidupan sehari-hari telah menjadi sangat penting. Oleh karena itu, penggunaan platform Media sosial sangat penting bagi sektor bisnis secara keseluruhan untuk menarik tujuan pelanggan (Jayasuriya, Azam, Khatibi, Atan, \& Dharmaratne, 2018)

Komunikasi yang semakin pesat mendorong setiap orang untuk mengakses berbagai informasi melalui berbagai media. Hal ini menjadi tantangan bagaimana Institusi Pendidikan Tinggi mampu berpikir secara kreatif bagaimana berkomunikasi di era digital. Menurut James C. Coleman \& Caoustatance L Hemen, dikatakan bahwa berfikir kreatif itu adalah proses menghasilkan karya baru, baik dalam bentuk cara atau metode, gagasan atau konsep, pemahaman, temuan ataupun karya seni (Rakhmat, 2008). Artinya, kreativitas tidak datang dengan sendirinya tanpa melalui proses berpikir.

Tidak terlepas dari cara memanfaatkan teknologi informasi dalam berkomunikasi kreatif kepada khalayak milenial. Media Sosial sebagai saluran teknologi informasi semakin memperkuat peran berkomunikasi secara kreatif bagi Institusi untuk bisa menjangkau calon mahasiswa, mahasiswa dan alumni secara interaktif melalui strategi komunikasi di Media Sosial.

Jaringan Media Sosial telah mengubah jalur interaksi antara pelanggan dan institusi karena setiap orang memiliki platform untuk terlibat dengan orang lain dan memberikan umpan balik dengan mudah karena akses yang lebih baik ke informasi barang dan jasa dan keputusan akhir pembelian (Wang, Yu, \& Wei, 2012). Maka di era digital, Institusi Pendidikan Tinggi semakin banyak berurusan dengan jejaring sosial seperti Facebook, Instagram dan Tiktok untuk mempengaruhi komunikasi dengan calon mahasiswa. Selain itu, unit penerimaan dan pemasaran Institusi Pendidikan Tinggi didasarkan pada Media Sosial untuk terlibat dengan siswa potensial dengan menetapkan kampanye promosi (Merrill, Social media for social research: Applications for higher education communications, 2011) 
Tingginya popularitas dan penggunaan Media Sosial di kalangan anak muda menjadikan Media Sosial sebagai wadah untuk menyampaikan informasi kepada calon mahasiswa oleh Institusi Pendidikan Tinggi. Di Institusi Pendidikan Tinggi, penggunaan Media Sosial juga merupakan perkembangan yang signifikan dalam menyajikan informasi kepada calon mahasiswa. Selain itu, penetrasi Media Sosial menggali persepsi alumni, mahasiswa saat ini dan orang tua dalam mencari informasi terkait Institusi Pendidikan Tinggi (Clark, Fine, \& Scheuer, 2016).

Terkait penyampaian informasi kepada calon mahasiswa, beberapa perguruan tinggi menyadari bahwa mempertahankan eksistensi melalui platform, seperti Facebook, sangat bermanfaat untuk proses rekrutmen, retensi, visibilitas, dan membangun kepercayaan calon mahasiswa (Peruta \& Shields, Marketing Your University on Social Media: a Content Analysis of Facebook Post Types and Formats, 2018).

Di penelitian sebelumnya menemukan bahwa konten menjadi penting dalam mencapai tujuannya (Ramadanty, Safitri , \& Suhendra, 2020), namun perlu dicermati bagaimana membangun konten agar relevan dengan kondisi yang ada sehingga dapat membangun engagement yang kuat dengan audiensnya. Hal ini sejalan dengan hasil penelitian sebelumnya yang menekankan pada tujuan Media Sosial untuk membangun engagement dengan audiens (Peruta \& Shields, 2018) (Figueira, 2018) (Oliveira \& Figueira, 2015) (Kumar \& Nanda, 2018) (Peruta \& Shields, 2018)

Bicara tentang persaingan Institusi Pendidikan Tinggi, melansir laman Top Universities QS WUR 2022 memberikan analisa terhadap 1.300 Institusi Pendidikan Tinggi top dunia yang berada di 97 Negara. Hasil rilis QS WUR 2022, (Bramasta, 2021) ada 16 perguruan tinggi Indonesia terbaik dunia. Tentunya hal ini menjadi tantangan bagi Institusi Pendidikan Tinggi di Indonesia untuk memberikan Pendidikan berkualitas bagi khalayak publik.

Banyak para ahli telah mengadopsi definisi dan konsep yang berbeda tentang apa itu Media Social. Dalam kajian pustaka ini, Penulis mencantumkan beberapa definisi tentang Media Sosial. Menurut (Miller, 2016), Media Sosial sebagai "scalable sociality", didefinisikan sebagai tolak ukur dalam kehidupan bersosialisasi di masyarakat. Menurut (Clark, Algoe, \& Green, 2017) Media Sosial sebagai "social network sites and well-being", didefinisikan sebagai situs jejaring sosial yang dijadikan sebagai alat konstruksi yang dapat mendorong hubungan individu secara dinamis dalam mengidentifikasi profile perilaku pengguna yang dapat memberikan dampak kuntungan dan kerugian serta menjadi pusat penyebarkan pengetahuan untuk memberkan tindakan kepada pengguna situs.

Sifat dan nomenklatur koneksi ini dapat bervariasi dari satu situs ke situs lainnya. Menurut (Obar \& Wildman, 2015), Media Sosial sebagai "user-generated content", Mendefinisikan jejaring Media Sosial sebagai jaringan berbasis web dengan layanan "user-generated content" sebagai sumber kehidupan Media Sosial yang memfasilitasi pengembangan jejaring sosial online dengan menghubungkan profil dengan profil individu dan atau kelompok lain.

Selain itu, Safko \& Brake mendefinisikan Media Sosial sebagai praktik, aktivitas, dan perilaku di antara masyarakat dari orang-orang yang berkumpul secara daring untuk berpartisipasi dalam informasi, opini, dan pengetahuan menggunakan media percakapan (Çiçek \& Erdogmus, 2012).

Dalam beberapa tahun belakangan ini, Media Sosial telah menjadi alat utama komunikasi Institusi Pendidikan Tinggi dalam menjalin hubungan dengan publik, hal ini juga telah digambarkan pada penelitian sebelumnya bahwa Institusi Pendidikan Tinggi telah memaksimalkan Media Sosial sebagai platform web utama.

(Nazeer, 2017) (Hossain \& Sakib, 2016) (Merrill, 2011) Kehadiran Media Sosial memberikan Insitusi Pendidikan Tinggi untuk dapat menjangkau calon mahasiswa dan menjaga komunikasi dengan mahasiswa dan alumni.

Di sisi lain, kehadiran media digital bukan berarti menggantikan interaksi fisik, interaksi yang terjadi di Media Sosial dapat menciptakan relasi (Shields \& Peruta, 2019), sebagai penguat interaksi yang sudah ada atau yang akan datang.

Salah satu faktor yang menentukan pemilihan Institusi Pendidikan Tinggi adalah pengalaman yang diperoleh calon mahasiswa dan orang tua ketika mengakses Media Sosial dan Website.

Oleh karena itu, pemasaran melalui Media Sosial di era digital ini menjadi salah satu alat penting yang harus diperhatikan oleh Institusi Pendidikan Tinggi. Persaingan antara Institusi Pendidikan Tinggi di Indonesia semakin ketat dan harus mampu memberikan keunggulan masing-masing untuk mendapatkan calon mahasisa yang berkualitas (Oliveira \& Figueira, 2015). Media Sosial dinilai memiliki pengaruh yang signifikan dalam 
meningkatkan keterlibatan mahasiswa atau calon mahasiswa ke Institusi Pendidikan Tinggi (Peruta \& Shields, 2016) (Peruta \& Helm , 2018).

Dalam membuat strategi Media Sosial untuk Institusi Pendidikan Tinggi, tujuan dari strategi tersebut diharapkan memiliki keterkaitan dengan segmentation, targeting, dan positioning Institusi. Segmentasi, penargetan dan positioning, memainkan peran penting dalam meningkatkan efektivitas strategi Media Sosial (Sheth , 2018) (Nanda, 2018.).

Saluran untuk menyampaikan informasi di Media Sosial merupakan faktor penting dalam strategi Media Sosial. Facebook dan Instagram dinilai lebih efektif untuk membangun interaksi dan engagement yang berkelanjutan antara mahasiswa dengan Institusi Pendidikan Tinggi (Chugh \& Ruhi, 2017) (Assimakopolous, Antoniadis, Kayas, \& Dvizac, 2017) (Alhabash \& Ma, 2017) (Simpson, Manago, Gaggi, \& Lynch, 2018).

Pandemi COVID-19 juga membawa pengaruh yang sangat besar bagi dunia pendidikan. Tidak hanya berdampak pada pengajaran saja, dalam memperoleh calon mahasiswa baru pun terdampak, sehingga dituntut harus berpikir kreatif untuk dan memberikan solusi masa depan melalui penyajian informasi tentang keunggulan pendidikan tinggi dan membangun hubungan berkelanjutan antara mahasiswa, orang tua, alumni dan khalayak publik.

Oleh karenanya bagaimana peran teknologi informasi yang mumpuni untuk membangun layanan informasi secara daring hingga segala transaksi kebutuhan perkuliahan secara daring. Bagaimana pemanfaatan platform Media Sosial sebagai komunikasi kreatif Institusi Pendidikan Tinggi Indonesia di masa pandemi COVID-19.

Tujuan dari penelitian ini adalah untuk menganalisis manajemen Media Sosial dalam komunikasi kreatif dan menentukan strategi yang digunakan untuk mempengaruhi penguatan keunggulan kompetitif di Institusi Pendidikan Tinggi.

\section{Landasan Konseptual}

Evaluasi terhadap strategi yang diterapkan diharapkan dapat menunjukkan tingkat keberhasilan dan sebagai masukan untuk selanjutnya. Evaluasi dapat dilakukan dengan menggunakan alat manajemen Media Sosial, alat pemantauan dan pendengaran sosial, dan alat analitik Media Sosial. Salah satunya adalah dengan pendekatan Media Sosial ROI, mengelola dan mengukur penggunaan Media Sosial (Blanchard., 2011).

Media Sosial ROI menunjukkan dengan tepat fungsi Media Sosial untuk bisnis, mengukur hasilnya, dan mengoptimalkannya. Pendekatan ini menunjukkan bagaimana menghubungkan titik-titik antara strategi Media Sosial, pengembangan program, integrasi dengan inisiatif jangka pendek dan panjang lainnya, pelaksanaan, dan dampak bisnis - baik finansial maupun non-finansial. Media Sosial ROI yang memberikan solusi praktis untuk semuanya dari penataan program sampai menarik perhatian follower, dari mendefinisikan metrik sampai menangani krisis.

Dalam kajian pustaka ini, perlu dikaji dari sisi dengan cara konten menjadi merupakan sumber utama dalam aktifitas Media Sosial. Menurut (Hossain \& Sakib, 2016), relevansi konten dengan mereka memberikan pengutan loyalitas mereka antara Institusi Pendidikan Tinggi dan mahasiswanya. Konten yang sangat dekat dengan mahasiswa memberikan keefektifitasan secara maksimal.

Penelitian sebelumnya, (Demirer, 2017) berfokus pada analisis konten yang mencakup teks, gambar, video dan jenis konten lainnya. Penelitian (Peruta \& Shields, 2018) mendukung pernyataan sebelumnya dengan mendeskripsikan format dan topik dari Institusi Pendidikan Tinggi terkemuka di Amerika Serikat.

(Pringle \& Fritz, 2019) mengungkapkan bahwa semua jenis konten yang dibagikan di platform Media Sosial harus relevan dan sesuai dengan keinginan pelanggan, jika tidak maka engagement terhadap pelanggan tidak terjadi dan ditinggalkan.

(Chauhan \& Pillai , 2013) menjelaskan bahwa kreatifitas konten sangat berpengaruh terhadap engagement yang dijadikan sebagai ukuran dalam keterlibatan interaksi pelanggan dengan mereknya. 


\section{METODE PENELITIAN}

Penelitian ini bertujuan untuk melihat kineja Media Sosial di masa pandemi COVID-19 dengan meneliti aktifitas pergerakan kinerja Media Sosial. Dalam penelitian ini menggunakan metode analisa data dengan analisa data kualitatif untuk memberikan gambaran yang menyeluruh terhadap cakupan tentang apa saja yang ditemukan pada waktu pengumpulan data dari social media analytics. Menurut (Lovett, 2011) Social Media Analytics adalah metode analisis yang dapat membantu untuk mengumpulkan, memantau, mengukur, menilai, menganalisis, meringkas, dan memvisualisasikan kinerja Media Sosial sesuai dengan target yang disesuaikan dan spesifik dengan menggunakan alat dan kerangka kerja informatika.

Dalam penelitian ini menggunakan social media analytics melalui kinerja metrik (Blanchard, 2011) yaitu menganalisasi data yang dikategorikan menjadi kelompok Impressions, Audience Demographics \& Growth, Publishing Behavior, Engagement. Objek penelitian ini melihat semua unggahan aktifitas dari Facebook, Instagram dan Tiktok selama periode 1 Juli 2020 hingga 30 Juni 2021. Frekuensi unggahan dikumpul perhari dan dianalisa selama satu tahun.

Waktu pengambilan pergerakan data yang dikumpulkan dari rata perhari hingga selama setahun. Penelitian pergerakan dilihat rata-rata perbulan dari aktifitas facebook dan Instagram yang dilakukan selama setahun, selanjutnya dibandingkan periode data tersebut dengan data periode setahun sebelumnya.

Penelitian ini melihat menganalisa isi dan frekuensi unggahan di Facebook dan Instagram dengan mengumpulkan ungahan konten yang mendapatkan respon terbanyak dilihat dari rata2 perbulan dan dikumpulkan selama satu tahun. Penelitian yang dilakukan dilihat dari jumlah audience yang memberikan respon dengan menekan klik tautan, menekan klik Like, dan juga memberikan komentar terhadap apa yang sedang di unggah.

\section{HASIL DAN PEMBAHASAN}

Pandemi COVID-19 telah merubah tatanan kehidupan masyarakat yang dituntut harus berpikir kreatif untuk menjalankan kebiasaan hidup baru. Tidak terlepas bagaimana memanfaatkan teknologi dalam berkomunikasi kreatif kepada calon mahasiswa, mahasiswa dan alumni. Media Sosial sebagai saluran teknologi komunikasi semakin memperkuat peran berkomunikasi secara kreatif bagi institusi untuk bisa menjangkau target audiens secara interaktif melalui strategi komunikasi di Media Sosial.

Penelitian kualitatif ini mengeksplorasi lebih jauh implementasi komunikasi kreatif secara efektif. Peneliti mengikuti proses tinjauan sistematis yang bertujuan untuk merangkum, mengidentifikasi, dan mengevaluasi datadata dalam ukuran kinerja Media Sosial seperti jumlah followers, type of content, impression dan engagement di Institusi Pendidikan Tinggi.

Jangka waktu pengumpulan data ditentukan selama 1 (satu) tahun dari 1 Juli 2020 sampai 30 Juni 2021. Seperti yang disampaikan pada penelitian sebelumnya, Media Sosial dalam hal ini Instagram, Facebook dan Tiktok adalah saluran komunikasi paling penting untuk membangun keunggulan Institusi Pendidikan Tinggi dan membangun hubungan dengan calon mahasiswa, mahasiswa dan alumni dimasa pandemi COVID-19.

Jika Dilihat dari Gambar 1 digambarkan bahwa terjadi pertumbuhan jumlah followers 55,8\% dibandingkan dengan tahun sebelumnya. Terjadi juga pertumbuhan dalam jumlah unggahan yang terpublikasi sebesar $81 \%$ dibandingkan tahun lalu sebelum pandemi COVID-19. Pertumbuhan Impression pun terjadi sebesar 107.8\% dibandingkan sebelum pandemi COVID-19. 


\begin{tabular}{|c|c|c|c|c|c|c|}
\hline Profile & Followers & $\begin{array}{l}\text { Net Follower } \\
\text { Growth }\end{array}$ & $\begin{array}{r}\text { Published Posts } \\
\& \text { Stories }\end{array}$ & Impressions & Engagements & $\begin{array}{l}\text { Engagement } \\
\text { Rate (per } \\
\text { Impression) }\end{array}$ \\
\hline Reporting Period & 57,385 & 21,991 & 1,636 & $47,700,115$ & 197,452 & $0.4 \%$ \\
\hline Jul 1, 2020 - Jun 30, 2021 & ス55.8\% & 入13.5\% & フ $81 \%$ & 入 $107.8 \%$ & $\searrow 16.4 \%$ & $\searrow 59.8 \%$ \\
\hline Compare to & 36,841 & 19,382 & 904 & $22,954,879$ & 236,115 & $1 \%$ \\
\hline
\end{tabular}

Gambar 1. Metrik Kinerja Media Sosial (Instagram)

(Sumber: Google Analytic)

Jika Diihat dari Gambar 2 digambarkan bahwa terjadi pertumbuhan Impression sebesar 114,7\% dibandingkan sebelum pandemi COVID-19. Terjadi pertumbuhan engagement sebesar 182,4 \%. Post link Clicks juga bertumbuh sebesar $145.1 \%$ dari tahun lalu. Engagement Rate (per impression) sebesar $31.5 \%$ dari $1 \%$ tahun lalu menjadi $1,3 \%$.

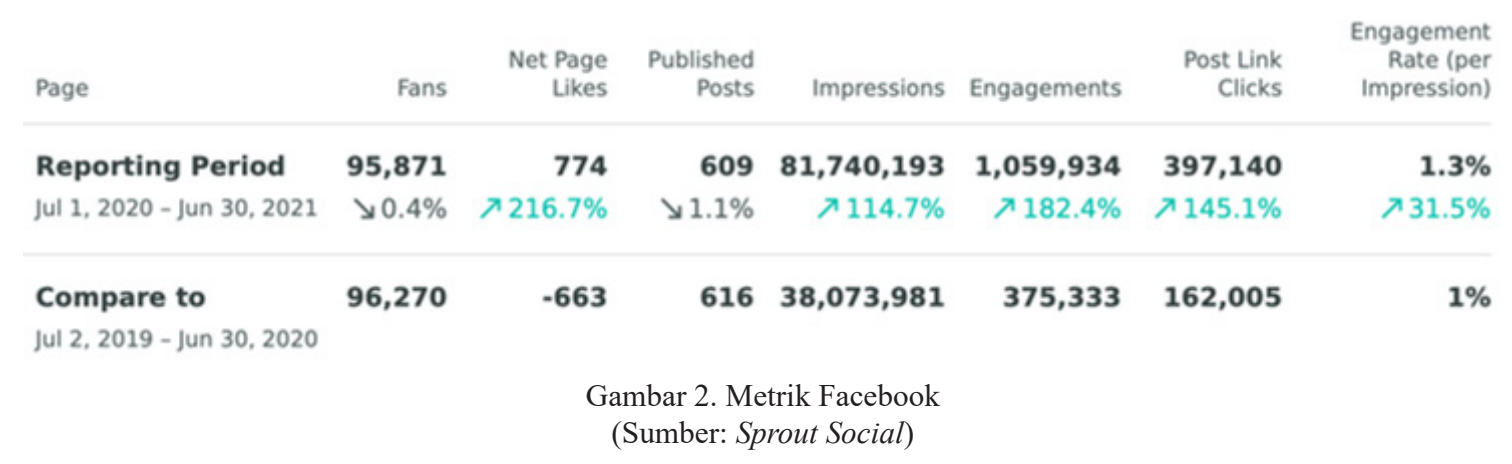

Berdasarkan manajemen Media Sosial di Institusi Pendidikan Tinggi pada penelitian Instagram, Facebook, Website dan Tiktok di dalam periode 1 Juli 2020 sampai 30 Juni 2021 dilihat dari kinerja content behaviour, audience growth, impression, engagement.

\section{Kinerja Konten}

Dipenelitian sebelumnya menemukan bahwa konten menjadi penting dalam mencapai tujuannya, namun perlu dicermati bagaimana membangun konten agar relevan dengan kondisi yang ada sehingga dapat membangun engagement yang kuat dengan audiensnya. Hal ini sejalan dengan hasil penelitian sebelumnya yang menekankan pada tujuan Media Sosial untuk membangun engagement dengan audiens (Peruta \& Shields, Marketing Your University on Social Media : a Content Analysis of Facebook Post Types and Formats, 2018) (Figueira, 2018) (Oliveira \& Figueira, 2015) (Peruta \& Shields, Social Media in Higher Education : Understanding How Colleges and Universities Use Facebook, 2016) (Kumar \& Nanda, Social Media in Higher Education: A Framework for Continuous Engagement, 2018).

Dari analisa konten yang dilakukan dimasa periode, berikut jenis konten yang memiliki relevansi dan engagement yang kuat dengan beberapa kelompok konten tentang social Distancing; di rumah aja, kuliah online, tips-tips, kehidupan kuliah online, kegiatan perkuliahan online (Class, ujian, thesis, sidang, konsultasi), info siaga COVID-19.

Kategori konten lainnya adalah yang menjelaskan tentang kehidupan kampus, kegiatan dan acara kemahasiswaan, serta akomodasi merupakan elemen penting dalam membantu calon mahasiswa mendapatkan kesan untuk memilih kampus. Dilihat dari analisa Instagram terjadi pertumbuhan konten sebesar $81 \%$ dengan pendekatan jenis konten carousels, video dan photo.

Hal menarik dari data yang ada, format video tumbuh hingga $120,4 \%$ dan format foto tumbuh $77,8 \%$. Dalam Analisa Instagram terjadi pertumbuhan sebesar 480,1\%. Dalam Facebook kontribusi total postingan sebesar 609 dengan pertumbuhan format foto $6,9 \%$ sebesar 357 unggahan.

Format video memberikan kontribusi sebesar 218 postingan dan kontribusi, Bisa diartikan bahwa kontribusi pertumbuhan konten ini sebagai kegiatan komunikasi kreatif dengan memanfaatkan Media Sosial dalam masa pandemi di Institusi Pendidikan Tinggi. 
Ini adalah frekuensi unggahan yang optimal untuk menjaga kualitas konten untuk mendapatkan umpan balik yang maksimal dan sangat disarankan untuk meningkatkan engagement kepada audiens. Berdasarkan hasil penelitian sebelumnya dijelaskan bahwa berapapun jumlah unggahan, kualitas konten yang diposting akan meningkatkan engagement terhadap audiens di Institusi Pendidikan Tinggi (Peruta \& Shields, Marketing Your University on Social Media: a Content Analysis of Facebook Post Types and Formats, 2018).

\section{Impression \& Engagement}

Jika dilhat dari Gambar 3 bahwa selama masa pandemi COVID-19, pemanfaatan Media Sosial di Instagram mencapai impression dengan pertumbuhan 107,8 \%, dengan rata-rata daily impression 107,8\%. Rata2 daily reach sebesar 136,1\%. Di Facebook juga terjadi pertumbuhan sebesar 114.7\%. Pertumbuhan terjadi pada organic impression 110,2\%. Paid Impression sebesar 114,9\%. Rata-rata daily impression per page sebesar 114,7\%. ratarata daily reach per page tumbuh $101 \%$.

\section{Impressions \\ Review how your content was seen by the Instagram community during the reporting period.}

\section{Impressions, by Month}

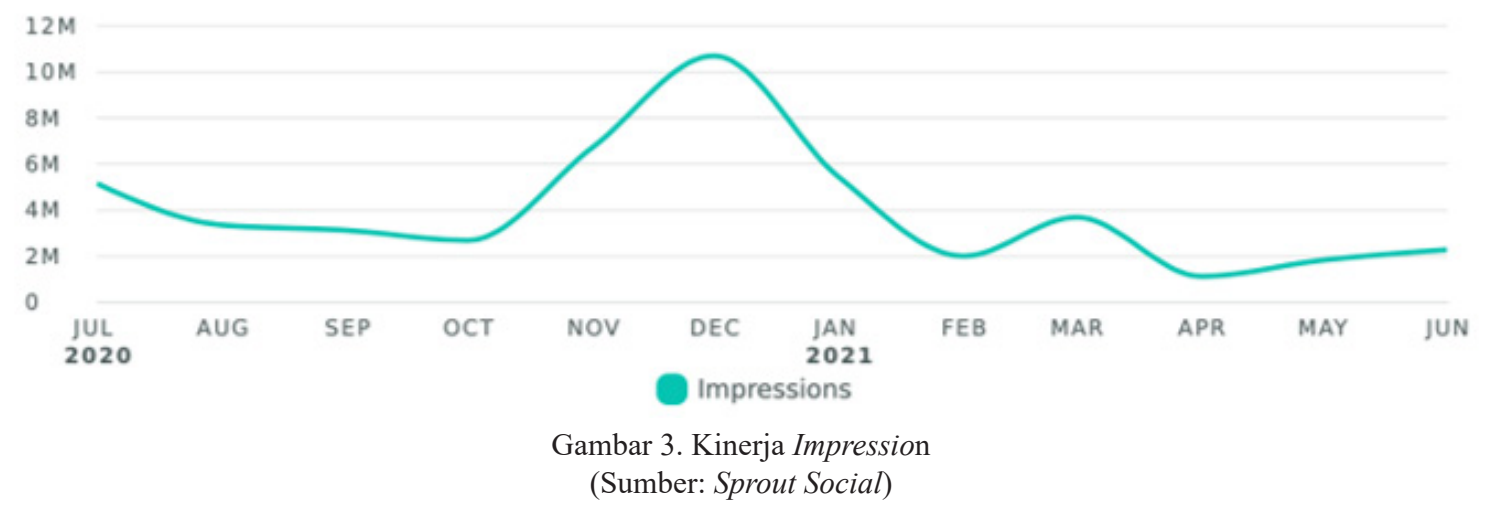

Penulis juga menganalisa enggagement audiens terhadap konten-konten yang di unggah ke Instagram selama masa pandemi. Gambar 4, menggambarkan total engagement sebesar 197,542 yang terdiri dari 181,502 like, 2210 comment dan 13,572 7 yang menyimpan konten tersebut serta 166 yang mereply 366 .

Kontribusi terbesar terjadi pada audiens yang menyimpan konten tersebut sebesar 51,5\% dan yang mereply sebesar 93\% dibandingkan dengan periode sebelum masa pandemi. Engagement Rate mencapai 0,4\% selama periode masa pandemi.

Di Facebook terjadi pertumbuhan engagement sebesar 182,4\% dengan engagement rate sebesar 1,3\%. Jika dilihat dari enggament rate terlihat bahwa di Facebook engagement lebih kuat dibandingkan di Instagram.

\section{Engagement}

See how people are engaging with your posts and stories during the reporting period.

\section{Engagements Comparison, by Month}

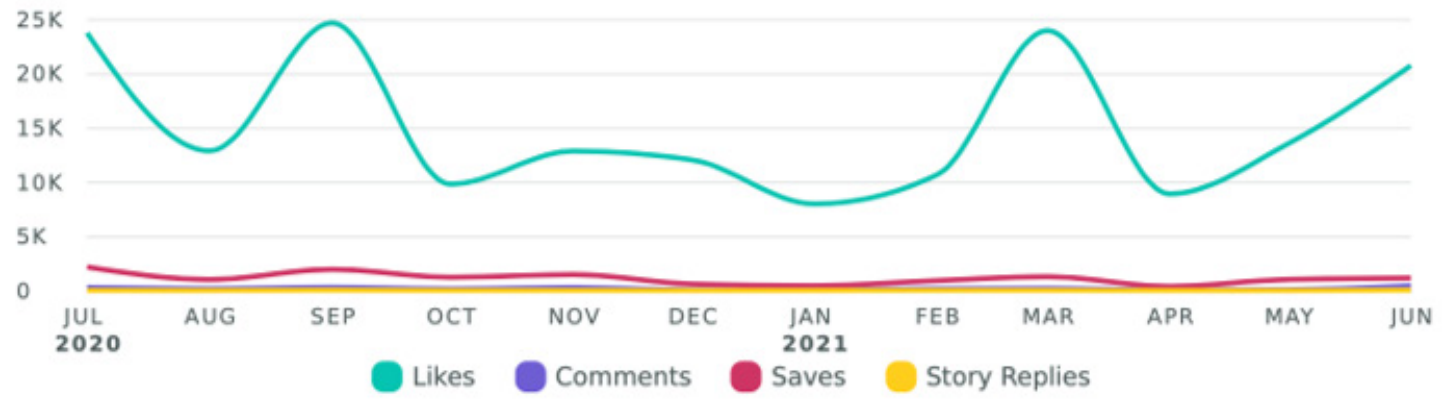

Gambar 4. Kinerja Engagement

(Sumber: Sprout Social) 
Selain menggunakan metode analisis konten, hasil penelitian juga dibandingkan dengan hasil data dari akun analitik Facebook dan Instagram pada periode tahun sebelumnya. Berdasarkan data dari Sprout Social diketahui bahwa di Instagram terjadi pertumbuhan followers sebesar 55.76\% yang tergambar di Gambar 5 .

\section{Audience Growth}

See how your audience grew during the reporting period.

Net Follower Growth Breakdown, by Month

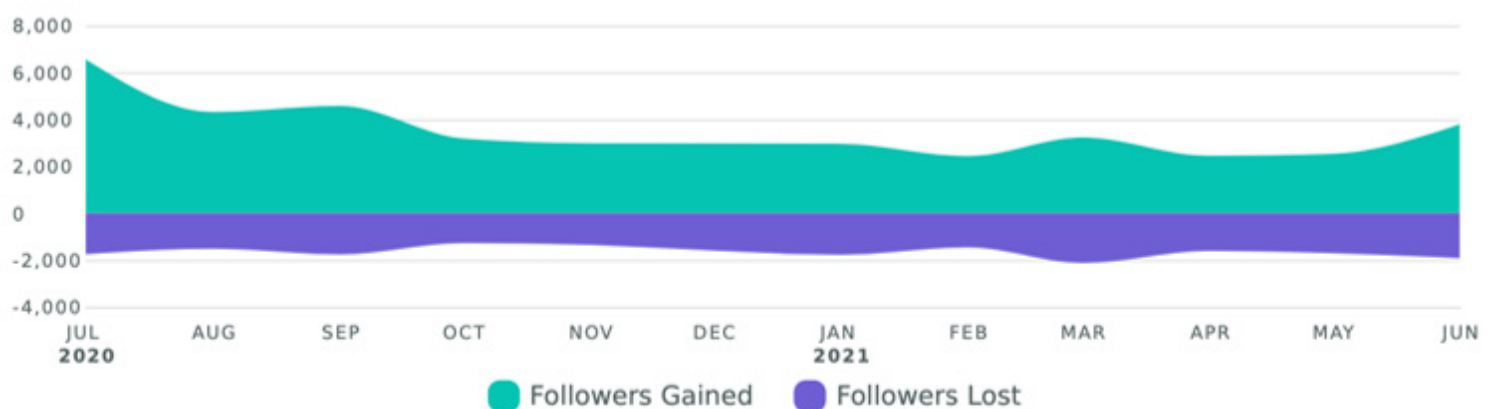

Followers Gained Followers Lost

Gambar 5. Kinerja Audience Growth

(Sumber: Sprout Social)

Berdasarkan data dari Sprout Social diketahui bahwa pertumbuhan jumlah followers terbagai dalam usia baik Facebook maupun Instagram mayoritas rata-rata usia pengunjung antara usia 18-24 tahun dan 25-34 tahun adalah khalayak milenial. 45-60 tahun terdiri dari 6,7\% untuk target orang tua yang akan mencari informasi kuliah untuk anak-anaknya.

Pengunjung tersebut tersebar di berbagai kota di Indonesia. Jika dilihat olahan data pengujung tersebar ke 45 kota di Indonesia diantaranya diambil 10 kota pengunjung terbesar seperti Jakarta, Tangerang, Bekasi, Depok, Medan, Bandung, Batam, Bogor, Pekanbaru, Surabaya dan Makassar. Dalam hal ini dengan memanfaatkan Media Sosial dimasa pandemi ini bisa menjangkau ke 45 kota di Indonesia.

Dalam penelitian ini, menemukan cara pemanfaatan Media Sosial sebagai komunikasi kreatif di masa pandemi COVID-19 ini adalah sangat memberikan pengaruh terhadap pertumbuhan audiens ke website Institusi Pendidikan Tinggi.

Dari hasil analisa data yang diambil dari data Google Analytic periode juli 2020-juli 2021, didapatkan terjadi pertumbuhan pengunjung website baru 699,33\% dengan berkunjung ke halaman bertumbuh hingga 400,57\% dengan rata-rata durasi 2 menit. Jika dilihat dari data sumber pertumbuhan tersebut, Media Sosial memberikan kontribusi sebesar 254,87\% kepada jumlah total pengunjung yang tergambar dalam Gambar 6 .

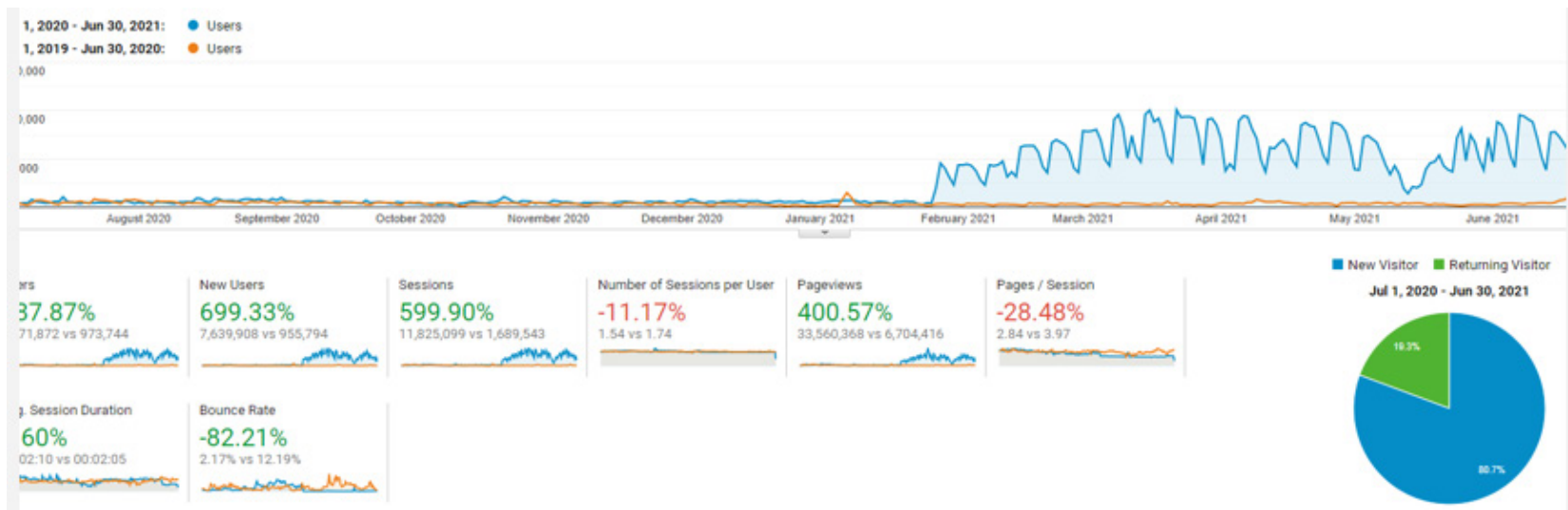

Gambar 6. Profil Audience

(Sumber: Google Analytics)

Di sisi lain terlihat potensi Tiktok sebagai Media Sosial yang pertumbuhannya pesat belakangan ini dan menjadi perhatian Institusi Pendidikan Tinggi untuk mulai dan memaksimalkan Tiktok sebagai media berkomunikasi secara kreatif dengan calon mahasiswa, mahasiswa dan alumni. 
Hal ini dilakukan di Insitusi Pendidikan Tinggi untuk menyebarkan informasi dan keunggulan Insitusi Pendidikan Tinggi. Melihat dari data statistik analitik Tiktok, periode 3 bulan terakhir terjadi pertumbuhan follower sebesar 1,117, total engagement video view sebesar 109,8k, profile view 5,673, likes 2616, 75 comment dan share 860. Secara demografi didominasi oleh perempuan sebesar $67.2 \%$ dan laki-laki sebesar 32,8\%.

Dari data petumbuhan yang begitu sangat cepat, penulis menganalisa bahwa teknologi canggih yang digunakan oleh pengembang aplikasi Tiktok menyajikan pola algoritma proses yang berbeda dari media sosial lainnya. Pengguna video yang disajikan cocok dengan kebutuhan dan minat pengguna secara tepat.

Selain itu pengguna diberikan kebebasan untuk melakukan share video yang mereka lihat di Tiktok dengan berbagai cara dan mudah dilakukan. Tiktok jadi media komunikasi yang kreatif dan efektif karena Indonesia merupakan pengguna aplikasi Tiktok terbesardi dunia, aplikasi Tiktok mudah digunakan, aplikasi Tiktok merupakan salah satu media sosial yang banyak dimiliki oleh pengguna generasi milenial, generasi $\mathrm{Y}$ dan $\mathrm{Z}$ dan fitur iklan Tiktok yang unik dan dapat menjangkau pasar lebih luas.

Strategi manajemen keseluruhan Media Sosial dilakukan untuk meningkatkan engagement. Manajemen Media Sosial yang baik diperlukan untuk melihat keterlibatan mahasiswa dan calon mahasiswa di Institusi Pendidikan Tinggi. Strategi manajemen Media Sosial yang sesuai dengan kebutuhan dan dapat memenuhi kebutuhan informasi mahasiswa dan calon mahasiswa akan meningkatkan pengakuan dari Institusi Pendidikan Tinggi.

\section{KESIMPULAN}

Pandemi COVID-19 telah merubah tatanan kehidupan masyarakat yang dituntut harus berpikir kreatif untuk menjalankan kebiasaan hidup baru. Tidak terlepas bagaimana memanfaatkan teknologi dalam berkomunikasi kreatif kepada khalayak milenial. Media Sosial sebagai saluran teknologi komunikasi semakin memperkuat peran berkomunikasi secara kreatif bagi institusi untuk bisa menjangkau khalayak milenial secara interaktif melalui strategi komunikasi di Media Sosial.

Seperti yang ditunjukkan oleh penelitian, menekankan bahwa Media Sosial dalam hal ini Instagram, Facebook dan Tiktok adalah saluran komunikasi paling penting untuk membangun keunggulan insitusi Pendidikan tinggi dan membangun hubungan dengan khalayak milenial di masa pandemi COVID-19.

Berdasarkan temuan penelitian, data-data dalam ukuran kinerja Media Sosial telah menciptakan pertumbuhan dari jumlah followers, jumlah dan jenis konten yang relevan, pertumbuhan impression serta engagement yang meningkat. Tentunya hal ini memberikan gambaran bagaimana manajemen Sosial Media dikelola dengan baik di Institusi Pendidikan Tinggi.

Penelitian ini merumuskan strategi manajemen keseluruhan Media Sosial dilakukan dengan menerapkan strategi konten yang relevan di masa pandemi COVID-19, strategi pertumbuhan audiens serta strategi membangun engagement secara efektif di Institusi Pendidikan Tinggi dalam memenuhi kebutuhan informasi serta meningkatkan kompetisi dan pengakuan masyarakat terhadap Institusi Pendidikan Tinggi. Di masa pandemi ini tentunya harus lebih relevan dengan kebutuhannya audiens.

Dari hasil Analisa, agar relevan di masa pandemi COVID-19 ini, maka komunikasi secara kreatif harus (1) Always On, harus selalu hadir dan memberikan dan memberikan nilai manfaat sesuai dengan kebutuhan audiens; (2) Found Online (Internet), mudah dicari ditemukan di dunia online; (3) Persona, memberikan informasi seesuai dengan kebutuhan. Value, memberikan nilai manfaat terhadap konten-konten yang di unggah; (4) Empathy/ care, harus memiliki rasa empati dan perhatian terhadap situasi yang ada; (5) Connecting and engagement harus terus berinteraksi dan saling memberikan umpan balik yang berkelanjutan, dan (6) Promising, harus mampu memberikan harapan dan janji agar dapat memenuhi kebutuhan.

Di masa pandemi COVID-19 ini tentunya Institusi Pendidikan Tinggi harus berpikir secara kreatif dengan melihat dan memanfaatkan teknologi terbaru melalui Media Sosial yang juga sekarang ini pertumbuhannya luar biasa. Tiktok menjadi salah satu cara komunikasi kreatif untuk membangun engagement dengan audiens.

Penelitian ini berimplikasi pada perkembangan pemanfaatan teknologi komunikasi khususnya dalam penggunaan dan pemanfaatan secara maksimal Media Sosial agar Institusi Pendidikan Tinggi menggunakan strategi manajemen Media Sosial yang tepat dan relevan sesuai dengan kondisi eksternal dan internal Institusi 
Pendidikan Tinggi terutama dimasa pandemi COVID-19 untuk meningkatkan engagement yang berkelanjutan kepada calon mahasiswa, mahasiswa saat ini dan alumni.

Kajian ini belum membandingkan dengan akun Media Sosial resmi Institusi Pendidikan Tinggi lainnya di Indonesia karena keterbatasan akses dan alat ukur kinerja Media Sosial yang tersedia.

\section{DAFTAR PUSTAKA}

Alhabash, S., \& Ma, M. (2017). A Tale of Four Platforms : Motivations and Uses of Facebook, Twitter, Instagram, and Snapchat Among College Students ? Journal Social Media + Society , 3(1), 1-13.

Assimakopolous, C., Antoniadis, I., Kayas, O. G., \& Dvizac, D. (2017). Effective Social Media Marketing Strategy : Facebook as an Opportunity for Universities. International Journal of Retail \& Distribution Management, 45(5), 532-549.

Blanchard., O. (2011). Social media ROI: managing and measuring social media efforts in your organization. Indianapolis, Ind.: Que.

Bramasta, D. B. (2021). Universitas Terbaik Di Indonesia Versi QS. Retrieved Agustus 2021, from kompas.com: https://www.kompas.com/tren/read/2021/06/10/134100065/16-universitas-terbaik-di-indonesia-versiqs-wur-2022-dan-skornya?page $=$ all

Chauhan, K., \& Pillai , A. (2013). Role of content strategy in social media brand communities: a case of higher education institutes in India. Journal of Product \& Brand Management, 22(1), 40-51.

Chugh , R., \& Ruhi, U. (2017). Social Media in Higher Education: A Literature Review of Facebook. Education and Information Technologies, 23(2), 605-616.

Çiçek, M., \& Erdogmus, I. E. (2012). The Impact of Social Media Marketing on Brand Loyalty. Social and Behavioral Sciences 58, $1353-1360$.

Clark, J. L., Algoe, S. B., \& Green, M. C. (2017). Social Network Sites and Well-Being: The Role of Social Connection. SAGE Journals, 32-37.

Clark, M. N., Fine, M. B., \& Scheuer, C. L. (2016). Relationship Quality in Higher Education Marketing: The Role of Social Media Engagement. Journal of Marketing for Higher Education, 27(1), 40-58.

COVID-19, S. T. (2021). Peta Sebaran. Retrieved Agustus 2021, from Covid19.go.id: https://covid19.go.id/peta-sebaran

Demirer, D. P. (2017). The Role of Content Strategy in Social Media on Brand Post's Popularity: a Case of Higher Education Institutions in Turkey. European Journal of Social Sciences vol. 9563, 134-143.

Figueira, A. R. (2018). Uncovering Social Media Content Strategies for Worldwide Universities Top-Ranked Universities. Journal Procedia Computer Science, 138, 663-670.

Granta , G., \& Scozzese, G. (2019). The Actions of e-Branding and Content Marketing to Improve Consumer Relationships. European Scietific Journal, 15(1), 58-72.

Hossain, S., \& Sakib, M. N. (2016). The Impact of Social Media Marketing on University Students' Brand Loyalty. International Journal of Marketing and Business Communication, 5(3), 1-7.

Kemendikbud. (2020). Surat Edaran Pencegahan COVID-19 Pada Satuan Pendidikan. Retrieved Agustus 2021, from kemdikbud.go.id: https://www.kemdikbud.go.id/main/blog/2020/03/surat-edaran-pencegahan-covid19-pada-satuan-pendidikan

Kumar, V., \& Nanda, P. (2018). Social Media in Higher Education: A Framework for Continuous Engagement. International Journal of Information and Communication Technology Education (IJICTE) 15(1), 109120.

Kumar, V., \& Nanda, P. (2018). Social Media in Higher Education: A Framework for Continuous Engagement. International Journal Information and Communication Technology, 15(1), 109-120. 
Merrill, N. (2011). Social media for social research: Applications for higher education communications. Emerald Group Publishing Limited, 25-48.

Merrill, N. (2011). Social media for social research: Applications for higher education communications. Emerald Group Publishing Limited.

Miller, D. (2016). Scalable sociality and "How the world changed social media": conversation with Daniel Miller. Consumption Markets \& Culture, 520-533.

Nanda, V. K. (2018.). Social Media in Higher Education , 15(1), 109-120,.

Nazeer, J. (2017). Impact of social media advertisements on university students. Arts Social Science Journal, 8(4), 290-296.

Obar, J. A., \& Wildman, S. S. (2015). Social Media Definition and the Governance Challenge - An Introduction to the Special Issue. Quello Center Working Paper 2663153, Telecommunications policy, 39(9), 745-750.

Oliveira, L., \& Figueira, A. R. (2015). Social Media Content Analysis in The Higher Education Sector: From Content to Strategy. International Journal of Web Portals, 7(2), 16-32.

Perindustrian, Kementerian. (2020). Pemerintah Optimalkan Peran Industri Pulihkan Ekonomi Nasional. Retrieved Agustus 2021, from kemenperin.go.id: https://kemenperin.go.id/artikel/22346/Pemerintah-Optimalkan-Peran-Industri-Pulihkan-Ekonomi-Nasional

Peruta, A., \& Helm , C. (2018). Engaging University Alumni Through Social Media: Strategies for Creating Community. The Journal of Social Media in Society Spring, 7(1), 123-150.

Peruta, A., \& Shields, A. B. (2016). Social Media in Higher Education : Understanding How Colleges and Universities Use Facebook. Journal of Marketing for Higher Education, 27(1), 131-143.

Peruta, A., \& Shields, A. B. (2018). Marketing your university on social media: A content analysis of Facebook post types and formats. Journal of Marketing for Higher Education, 28(2), 175-191.

Peruta, A., \& Shields, A. B. (2018). Social Media in Higher Education : Understanding How Colleges and Universities Use Facebook. Journal of Marketing for Higher Education, 27(1), 131-143.

Peruta, A., \& Shields, A. B. (2018). Marketing Your University on Social Media : a Content Analysis of Facebook Post Types and Formats. Journal of Marketing for Higher Education, 28(3), 175-191.

Pringle, J., \& Fritz, S. (2019). The university brand and social media: using data analytics to assess brand authenticity. Journal of Marketing for Higher Education, 29(1), 19-44.

Ramadanty , S., Safitri , Y., \& Suhendra, H. (2020). Social Media Content Strategy for Higher Education, Indonesia. In 2020 International Conference on Information Management and Technology (ICIMTech) (pp. 336-341). Jakarta: IEEE.

Sheth, J. N. (2018). How Social Media Will Impact Marketing Media. In Social Media Marketing (pp. 1-15).

Shields, A. B., \& Peruta, A. (2019). Social Media and The University Decision . Do Prospective Students Really Care ? Journal of Marketing For Higher Education, 29(1), 67-83.

Simpson, C. S., Manago , A., Gaggi, N., \& Lynch, K. F. (2018). Why Do College Students Prefer Facebook, Twitter, or Instagram? Site Affordances, Tensions Between Privacy and Self-Expression, and Implications for Social Capital. Journal Computers in Human Behavior, 86, 276-288.

Wang , X., Yu, C., \& Wei, Y. (2012). Social Media Peer Communication and Impacts on Purchase Intentions: A Consumer Socialization Framework. Journal of Interactive Marketing, 198-208.

WeAreSocial. (2021). Reports Digital 2021 Indonesia. Retrieved Agustus 2021, from datareportal.com: https:// datareportal.com/reports/digital-2021-indonesia

Zhu, Y. M. (2019). Social Media Engagement and Chinese International Student Recruitment : Understanding How UK HEIs Use Weibo and WeChat. Journal of Marketing for Higher Education, 29(2), 173-190. 